http://jmscr.igmpublication.org/home/ ISSN (e)-2347-176x ISSN (p) 2455-0450

crossref DOI: https://dx.doi.org/10.18535/jmscr/v10i1.09

Journal Of Medical Science And Clinical Research

\title{
Correlation between Plasma Homocysteine Level and Retinal Vein Occusion: A Case Control Study
}

Authors

\section{Dr Vinayak Ganesh Bhat MD ${ }^{1}$, Dr Rajkumar Patra MS $^{2^{*}}$}

${ }^{1}$ Assistant Professor, Department of Biochemistry, Maharajah's Institute of Medical Sciences, Nellimarla, Vizianagaram, Andhra Pradesh, India

${ }^{2}$ Assistant Professor, Department of Ophthalmology, Maharajah's Institute of Medical Sciences, Nellimarla, Vizianagaram, Andhra Pradesh, India

*Corresponding Author

\section{Dr Rajkumar Patra MS}

Assistant Professor, Department of Ophthalmology, Maharajah's Institute of Medical Sciences, Nellimarla, Vizianagaram, Andhra Pradesh, India

Abstract
Introduction: Retinal venous occlusion $(R V O)$ is very common condition affecting retinal vasculature.
It's caused by localized atherosclerosis and often associated with systemic disorders. Regular tests
showed Hyperhomocysteinemia is seen to be highly associated in patients with RVO along with other
systemic causes. Mild to moderate homocysteine levels thought to cause atherosclerosis in Retinal
vasculature by damaging the blood vessel wall. This study assesses the correlation between plasma
homocysteine and retinal vein occlusion.
Materials and Methods: this was a progressive case-control based study conducted in Maharajah's
Institute of Medical Sciences, Vizianagaram, Andhra Pradesh over a period of 1 year. 58 patients with
diagnosis of RVO were included in the study after exclusion criteria. Detailed ophthalmological
examination along with plasma Homocysteine levels were checked along with coagulation and
hematological tests. Patients were followed up for 1 year for progression of disease.
Results: there was a strong association between high levels of Homocysteine and RVO. A statistically
significant association was found (p < O.OO1) when compared to control. Analysis also revealed that
prevalence of rise in plasma homocysteine levels in cases of Central Retinal vein occlusion (CRVO)
(OR=13) compared to Branch Retinal Vein Occlusion (BRVO)(OR=5.03).
Conclusion: Hyperhomocysteinemia is more prevalent in CRVO than BRVO in our study subjects. So,
treatment of Hyperhomocysteinemia by folic acid and Vitamin B12 supplementation in RVO patients
should be considered.

\section{Introduction}

Retinal venous occlusion is very common condition affecting retinal vasculature. Its divided into two types. Central Retinal Venous Occlusion (CRVO) and Branch Retinal Vein Occlusion (BRVO). It's caused by localized atherosclerosis and often associated with systemic disorders. Both local (Raised intra ocular Pressure) and systemic risk factors (Hyperlipidemia, Hypertension, Diabetes mellitus) have been associated with $\mathrm{RVO}^{1}$. Among the types of RVO, CRVO has poorer prognosis than BRVO because of its sight of occlusion and type of consequent vascular damage. 
Especially in young patients, it's thought to be caused by hypercoagulability of blood. Biochemical and other laboratory tests have not accounted for this cause ${ }^{2}$. Regular tests done by Department of Biochemistry among all the parameters tested, Hyperhomocysteinemia is seen to be highly associated in patients with CRVO. Study conducted by Boyd et $\mathrm{al}^{3}$ reported that there is no significant increase in Von Willebrand factor (factor VIII) apart from homocysteine levels in cases of CRVO when compared to control subjects. Mild to moderate homocysteine levels have always been reported as risk factor for the development of atherosclerosis in Retinal, cerebral and coronary vasculature ${ }^{4,5,6,7}$. Clinical features seen depends on the degree and site of atherosclerosis. Homocysteine is found to damage the blood vessel wallin multifactorial pathway $8,9,10,11,12,13$

Hyperhomocysteinemia is caused by various reasons. It can be caused by a rare genetic defect due to deficiency of enzymes cystathione $\beta$ synthase (CBS) and methyltetrahydrofolate reductase. Even nutritional deficiencies like vitamin $\mathrm{B} 12$ and folate ${ }^{14}$ can cause mild Hyperhomocysteinemia as these vitamins play a key role in the Biochemical pathways.

All circulating Homocysteine is derived from Dietary methionine. Methionine acts as a methyl group donor as $\mathrm{S}$ adenosyl methionine (SAM). After receiving methyl group homocysteine becomes $\mathrm{S}$ adenosyl homocysteine ( $\mathrm{SAH}$ ) which is then converted back to Homocysteine. Homocysteine is a Sulphur containing non protein amino acid which is removed from blood in two ways.

1) Metabolized to cystathione by transsulfuration pathway which requires pyridoxine (Vitamin B6) ${ }^{15,16}$

2) Converted back to methionine with the help of Vitamin B12 and folate. It requires transmethylation reaction ${ }^{15,16}$.

There were also some contradictory reports suggesting the hypothesis that Hyperhomocysteinemia causes RVO ${ }^{17,18}$. so, to evaluate the correlation, current study was conducted for 1 year.

\section{Materials and Methods Study Design}

A 1-year prospective case-control study was conducted in patients with diagnosis of CRVO. Study excluded those patients with other local or systemic diseases. This study was conducted in coordination of Department of Biochemistry and Department of Ophthalmology in Maharajah's Institute of medical sciences (MIMS), Nellimarla, Vizianagaram, Andhra Pradesh, India. Institutional ethical committee approval was takenfor the study. All the patients who participated in the study have been explained the study in their own language and informed consent was taken. These were the patients who visited regular OPD in MIMS with history suggesting CRVO.

A detailed history was taken by the participants which included family history, Dietary habits, other habits like smoking, alcohol intake, history of systemic and other ocular diseases, drug history. Exclusion criteria included Diabetes mellitus, Hypertension, cardio vascular disease, high cholesterol, liver disease, renal disease, Coagulation and other hematological abnormalities as per Biochemical and Hematological tests conducted in the subjects.

Both eye ophthalmological examination was done. Visual acuity, relative afferent pupillary defect (RAPD), slit lamp bio microscopy and fundus examination was used to clinically diagnose RVO. 102 patients participated in the study. After thoroughly screening of inclusion and exclusion criteria, 58 patients were included in the study among which 21 had CRVO and 37 had BRVO. 50 subjects were taken as control who didn't have RVO. None of the study subjects had any history of major thromboemolitic disease.

\section{Biochemistry Testing}

Patients were told to do overnight fasting. Venous blood sample was taken into EDTA containing 
tube in Department of Biochemistry. Plasma was separated immediately by centrifugation at $1000 \mathrm{x}$ $\mathrm{g}$ at $25^{\circ} \mathrm{C}$ for 3 minutes. Total plasma Homocysteine was estimated with reagent kit supplied by ERBA Mannheim clinical chemistry division.

Other biochemical tests were also done to subjects including Fasting plasma glucose, Lipid profile (LDL cholesterol, HDL cholesterol, VLDL Cholesterol, Total cholesterol, Triglycerides), Coagulation tests (CT, BT, PT), Hematological tests (TC, DC, ESR, Hb).

\section{Results}

In present study, Incidence of Hyperhomocysteinemia was also studied in current study. High homocysteine levels were found in 31 patients with RVO in which 14 were CRVO patients and 17 were BRVO patients. Normal homocysteine levels were found in 27 RVO patients in which 7 were CRVO and 20 were BRVO. In control subjects, 6 had high
Homocysteine levels and 36 had normal homocysteine levels.

mean \pm SD Plasma total homocysteine levels of $\mathrm{RVO}$ was found to be $18.21 \pm 5.48 \mu \mathrm{M} / \mathrm{L}$ as compared to control $12.51 \pm 2.14 \mu \mathrm{M} / \mathrm{L}$. When studied in detail, mean \pm SD Plasma total homocysteine levels of CRVO was found to be $19.04 \pm 5.15 \mu \mathrm{M} / \mathrm{L}$ as compared to control $12.51 \pm$ $2.14 \mu \mathrm{M} / \mathrm{L}$. mean \pm SD Plasma total homocysteine levels of BRVO was found to be 17.39 \pm 5.82 $\mu \mathrm{M} / \mathrm{L}$ as compared to control $12.51 \pm 2.14 \mu \mathrm{M} / \mathrm{L}$. so it was found that, levels of Homocysteine levels were significantly high in RVO patients when compared to control subjects. ( $\mathrm{P}<0.001)$. analysis also showed that an elevated homocysteine level was a risk factor for RVO with an $\mathrm{OR}=7.36$.

It was seen that; Homocysteine levels were higher in CRVO than BRVO. Analysis also showed that Hyperhomocysteinemia is associated with increased incidence of CRVO $(\mathrm{OR}=13)$ compared to $\mathrm{BRVO}(\mathrm{OR}=5.03)$

Table 1 Mean total homocysteine levels in RVO and control subjects

\begin{tabular}{|c|c|c|}
\hline Parameter & RVO (mean $\pm \mathrm{SD})(\mu \mathrm{M} / \mathrm{L})$ & Control $($ mean $\pm \mathrm{SD})(\mu \mathrm{M} / \mathrm{L})$ \\
\hline Plasma total homocysteine & $18.21 \pm 5.48$ & $12.51 \pm 2.14$ \\
\hline
\end{tabular}

Fig. 1 Comparison of plasma total homocysteine levels between RVO of cases and control

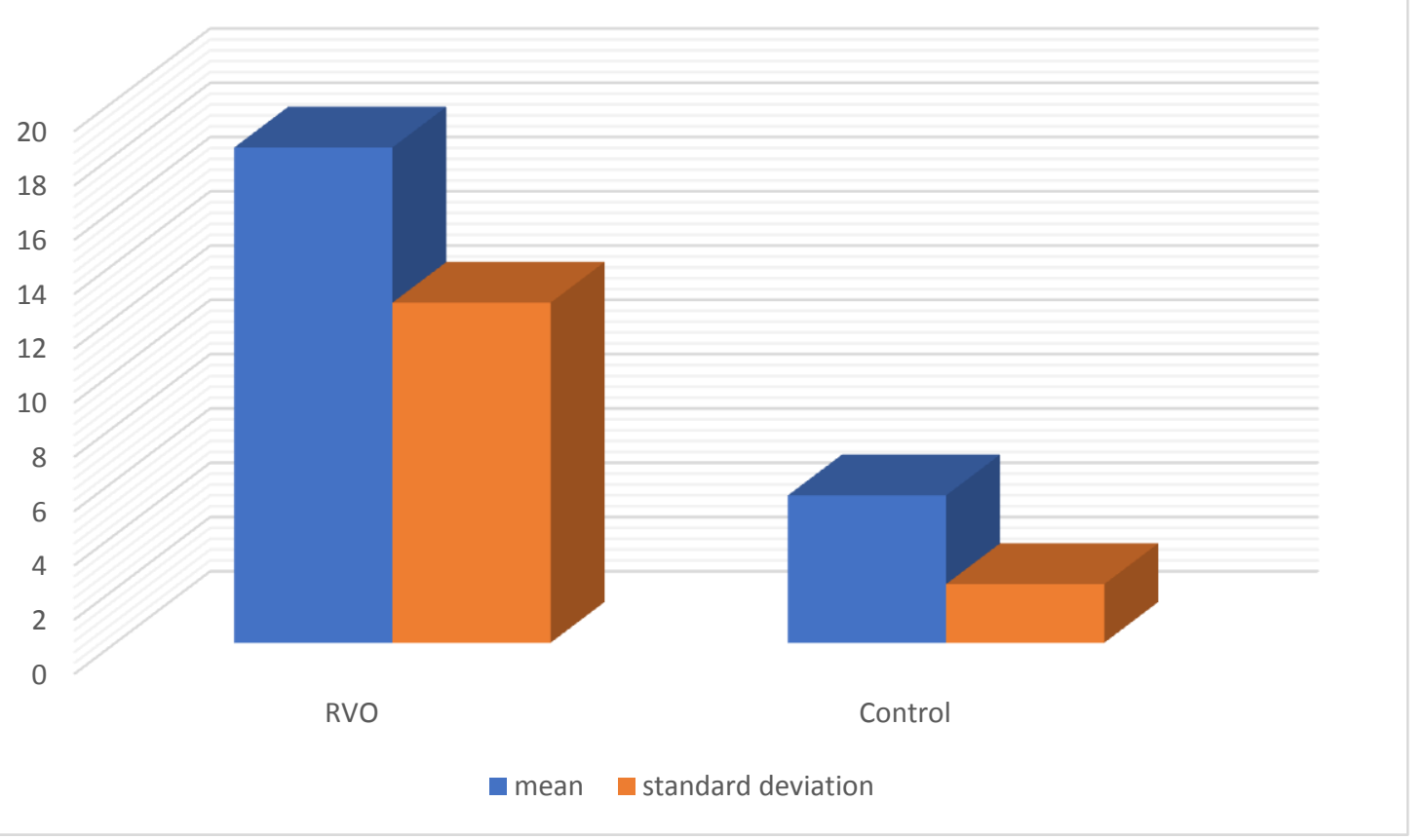


Table 2 Incidence of Hyperhomocysteinemia in RVO compared to control

\begin{tabular}{|l|l|l|}
\hline Parameter & RVO & Control \\
\hline High homocysteine & 31 & 6 \\
\hline Normal homocysteine & 27 & 36 \\
\hline total & 58 & 42 \\
\hline OR $=7.36$ for RVO &
\end{tabular}

Table 3 Mean Total homocysteine levels in CRVO, BRVO and control subjects

\begin{tabular}{|l|c|c|c|}
\hline Parameter & $\begin{array}{c}\text { CRVO }(\text { mean } \pm \text { SD }) \\
(\mu \mathrm{M} / \mathrm{L})\end{array}$ & $\begin{array}{c}\text { BRVO }(\text { mean } \pm \mathrm{SD}) \\
(\mu \mathrm{M} / \mathrm{L})\end{array}$ & $\begin{array}{c}\text { Control }(\mathrm{mean} \pm \mathrm{SD}) \\
(\mu \mathrm{M} / \mathrm{L})\end{array}$ \\
\hline $\begin{array}{l}\text { Plasma } \\
\text { homocysteine }\end{array}$ & $19.04 \pm 5.15$ & $17.39 \pm 5.82$ & $12.51 \pm 2.14$ \\
\hline
\end{tabular}

Value expressed as mean \pm SD

$P<0.001$ as compared to control.

Fig 2 Mean Total homocysteine levels in CRVO, BRVO and control subjects

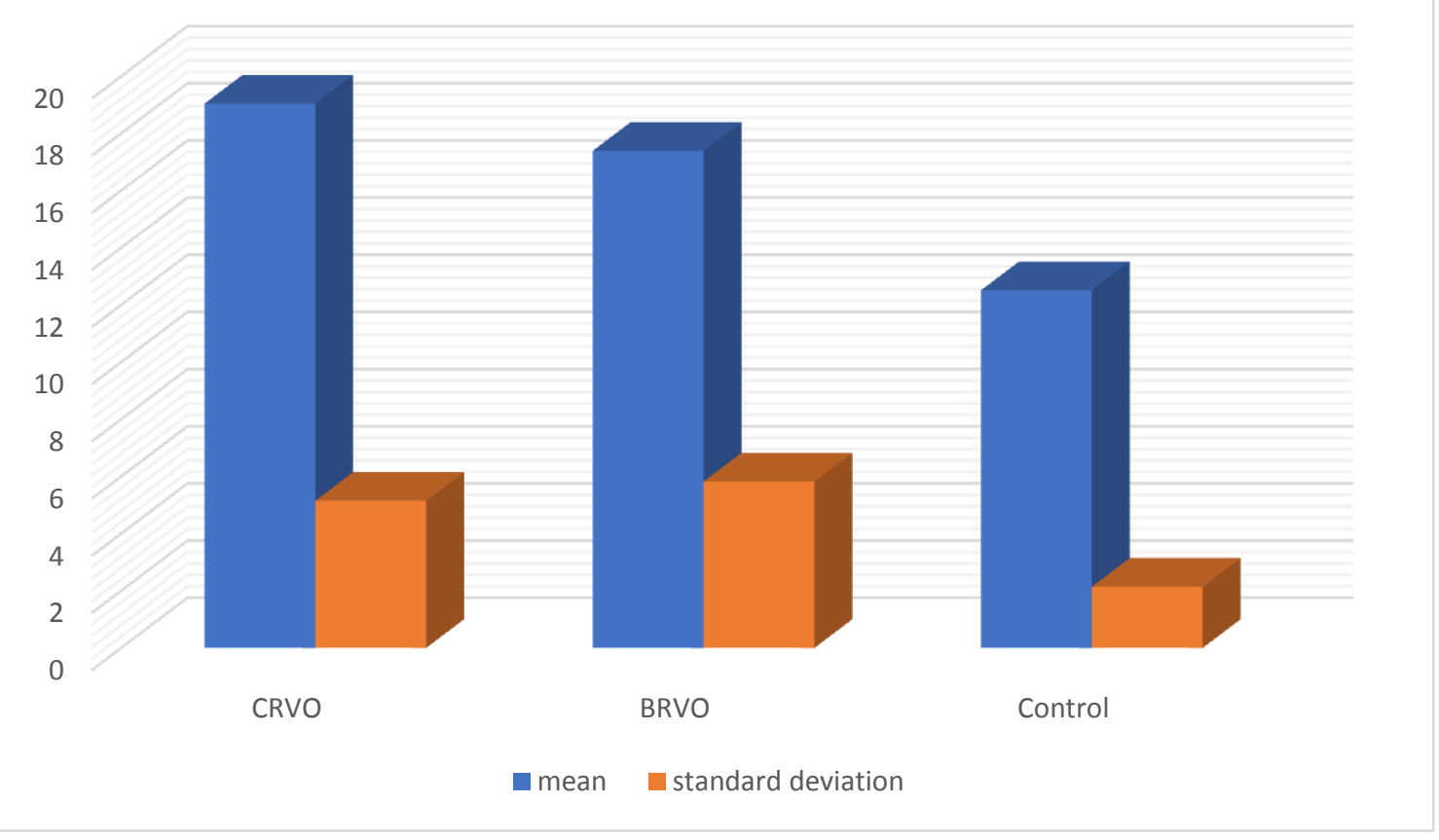

Table 4 Incidence of Hyperhomocysteinemia in CRVO and BRVO with respect to control

\begin{tabular}{|l|c|c|c|}
\hline Parameter & CRVO & BRVO & Control \\
\hline High homocysteine & 14 & 17 & 6 \\
\hline Normal homocysteine & 7 & 20 & 36 \\
\hline Total & 21 & 37 & 42 \\
\hline
\end{tabular}

\section{Discussion and Conclusion}

Some studies conducted in the world, strongly suggests Hyperhomocysteinemia as independent risk factor for $\mathrm{CRVO}^{18,19,20}$. Study conducted by Gao W et al ${ }^{21}$ reported and Odds ratio (OR) of 1.3 for fasting homocysteine levels with CRVO done in Chinese population and study done by Lattanzio et $\mathrm{al}^{14}$ reported OR of 3.0. meta-analysis done by Janssen et al ${ }^{22}$ has also shown an overall
OR of 8.9 for homocysteine. Another meta analytical study conducted by Cahill et $\mathrm{al}^{23}$ has shown that retinal vascular occlusion associated with increased plasma homocysteine and low serum folate levels. Study conducted by Poloshek et $\mathrm{al}^{24}$ explained the possibility of direct cytotoxic effect of homocysteine on retinal vascular endothelial cells. He has also reported methionine deficiency in subjects. 
There are various mechanisms, which explains endothelial dysfunction by homocysteine. It includes decreased bioavailability of nitric oxide ${ }^{9}$. Mitogenic effect on smooth muscle cells of $\operatorname{artery}^{10}$, Various thrombotic factors alter their expression, expression of acute stress related genes 11. homocysteine has sulfhydryl group, which has high pKa. So, homocysteine forms stable disulfide bonds with protein cysteine residues. Due to this reason, many proteins function is impaired. Molecular targets of homocysteine were found to be albumin, transthyretin, fibronectin, factor $\mathrm{V}$ and annexin $\mathrm{II}^{12}$. Homocysteine is also converted to chemically reactive metabolite, homocysteine- thiolactone, which contributes for toxicity leading to endothelial dysfunction ${ }^{13}$.

In this study, the patients with RVO showed a significant elevation of homocysteine when compared to control. It can be due to direct cytotoxic effect of homocysteine on retinal endothelial cells along with its prothrombotic effects. Vascular smooth muscle cells when exposed to high homocysteine, there is inflammatory response upregulation which causes atherogenesis and other adverse vascular defects ${ }^{25}$. There was complete exclusion of all major thromboembolitic defects and coagulation disorders. Even hematological and coagulation parameters were normal in study patients. Hence, homocysteine induced thrombosis may be a crucial factor which is triggering vascular occlusion ${ }^{26}$ which was also told by study done by Janssen et $\mathrm{al}^{22}$.

Hyperhomocysteinemia is more prevalent in CRVO than BRVO in our study subjects. So treatment of Hyperhomocysteinemia by folic acid and Vitamin B12 supplementation in RVO patients should be considered.

\section{Bibliography}

1. Kanski JJ. Clinical ophthalmology: a systematic approach. 6th ed. Philadelphia: Butterworth-Heinemann; 2007. p. 584-5.
2. Prisco D, Marcucci R. Retinal vein thrombosis: risk factors, pathogenesis and therapeutic approach. Pathophysiol Haemost Thromb. 2002; 32:308-11.

3. Boyd S, Owens D, Gin T, Bunce K, Sherafat H, Perry D, et al. Plasma homocysteine methylene tetrahydrofolate reductase C677T and factor II G2010A polymorphism, factor VIII and VWF in central retinal vein occlusion. $\mathrm{Br} \quad \mathrm{J}$ Ophthalmol. 2001; 85:1313-5.

4. Genser D, Prachar H, Hauer R, Halbmayer M, Mlczoch J, Elmadfa I. Homocysteine, folate and vitamin B12 in patients with coronary heart disease. Ann NutrMetab. 2006;50(5):413-9.

5. Pianka P, Almog Y, Man O, Goldstein M, Sela BA, Loewenstein A. Hyperhomocysteinemia in patients with nonarteric anterior ischemic optic neuropathy: central retinal artery occlusion and central retinal vein occlusion. Ophthalmology. 2000;107: 1588-92.

6. Wenzler EM, Rademakers AJ, Boers GH, Cruysberg JR, Webers CA, Deutman AF. Hyperhomocysteine in retinal artery and retinal vein occlusion. Am J Ophthalmol. 1993; 115:162-7.

7. Brown BA, Marx JL, Ward TP, Hollifield RD, Dick JS, Brozetti JJ, et al. Homocysteine: a risk factor for retinal venous occlusive disease. Ophthalmology. 2002;109(2):287-90.

8. Lentz R. Mechanisms of homocysteineinduced atherothrombosis. J ThrombHaemost. 2005; 3:1646-54.

9. Weiss N. Mechanisms of increased vascular oxidant stress in hyperhomocysteinemia and its impact on endothelial function. Curr Drug Metab. 2005;6(1):27-54.

10. Postea O, Krotz F, Henger A, Keller C, Weiss N. Stereospecific and redoxsensitive increase in monocyte adhesion to endothelial cells by homocysteine. 
Arterioscler Thromb Vasc Biol. 2006; 26(3):508-13.

11. Jakubowski H. Pathophysiological consequences of homocysteine excess. J Nutr. 2006;136(Suppl 6):1741S-9S.

12. Jacobsen DW, Catanescu O, Barbato JC. Molecular targeting by homocysteine: a mechanism for vascular pathogenesis. Clin Chem Lab Med. 2005;43(10):1076-83.

13. Selhub J. The many facets of hyperhomocysteinemia: studies from the Framingham cohorts. J Nutr. 2006; 136:1726S-30S.

14. Lattanzio R, Sampirtro F, Ramonia A, Fattorini A, Brancato R. Moderate hyperhomocysteinemia and early-onset central retinal vein occlusion. Retina. 2006;26(1):65-70.

15. Finkelstein JD. Inborn errors of sulfurcontaining amino acid metabolism. J Nutr. 2006;136(suppl 6):1750S-4S.

16. Burtis C. A., Ashwood, E.R., \& Bruns, D.E. (2012). Tietz textbook of clinical chemistry and molecular diagnostics. London: Elsevier Health Sciences

17. Pinna A, Carru C, Zinellu A, Dore S, Deiana L, Carta F. Plasma homocysteine and cysteine levels in retinal vein occlusion. Invest Ophthalmol Vis Sci. 2006;47(9):4067-71.

18. Chua B, Kifley A, Wong TY, Mitchell P. Homocysteine and retinal emboli the Blue Mountains eye study. Am J Ophthalmol. 2006;142(2):322-4.

19. Chau B, Kifley A, Wong TY, Mitchell P. Homocysteine and retinal vein occlusion: population based study. Am J Ophthalmol. 2005;139(1):181-2.

20. Di Crecchio L, Parodi MB, Sanguinetti G, Iacono P, Ravalico G. Hyper homocysteinemia and the methylenetetrahydrofolate reductase $677 \mathrm{C}$ $\mathrm{T}$ mutation in patients under 50 years of age affected by central retinal vein occlusion.

Ophthalmology.

2004;

111:940-5.

21. Gao W, Wang YS, Zhang P, Wang HY. Hyperhomocysteinemia and low plasma folate as risk factors for central retinal vein occlusion: a case-control study in a Chinese population. Graefes Arch Clin Exp Ophthalmol. 2006;244(10):1246-9.

22. Janssen MC, den Heijer M, Cruysberg JR, Wollersheim H, Bredie SJ. Retinal vein occlusion: a form of venous thrombosis or a complication of atherosclerosis? - a meta-analysis of thrombophilic factors. ThrombHaemost. 2005;93(6):1021-6.

23. Cahil MT, Stinnett SS, Fekrat S. Metaanalysis of plasma homocysteine, serum folate, serum vitamin B12, and thermolabile MTHFR genotype as risk factors for retinal vascular occlusive disease. Am J Ophthalmol. 2003; 136(6):1136-50.

24. Poloschek CM, Fowler B, Unsold R, Lorenz B. Disturbed visual system function in methionine synthase deficiency. Graefes Arch Clin Exp Ophthalmol. 2005;243(5):497-500.

25. Kerkeni M, Tnani M, Chuniaud L, Miled A, Maaroufi K, Trivin F. Comparative study on in vitro effects of homocysteine thiolactone and homocysteine on HUVEC Cells: evidence for a stronger proapoptotic and proinflammative homocysteine thiolactone. Mol Cell Biochem. 2006;291(1-2):119-26.

26. Undas A, Brozek J, Szczeklik A. Homocysteine and thrombosis: from basic science to clinical evidence. Thromb Haemost. 2005; 94(5):907-15. 